\title{
Immunological Defects in Neonatal Sepsis and Potential Therapeutic Approaches
}

\author{
Steven L. Raymond', Julie A. Stortz', Juan C. Mira', Shawn D. Larson', James L. Wynn ${ }^{2}$ \\ and Lyle L. Moldawer ${ }^{1 *}$
}

${ }^{1}$ Department of Surgery, University of Florida College of Medicine, Gainesville, FL, USA, ${ }^{2}$ Department of Pediatrics, University of Florida College of Medicine, Gainesville, FL, USA

Despite advances in critical care medicine, neonatal sepsis remains a major cause of morbidity and mortality worldwide, with the greatest risk affecting very low birth weight, preterm neonates. The presentation of neonatal sepsis varies markedly from its presentation in adults, and there is no clear consensus definition of neonatal sepsis. Previous work has demonstrated that when neonates become septic, death can occur rapidly over a matter of hours or days and is generally associated with inflammation, organ injury, and respiratory failure. Studies of the transcriptomic response by neonates

OPEN ACCESS

Edited by: Vineet Bhandari, Drexel University College of Medicine, USA

Reviewed by: Salvatore Andrea Mastrolia, University of Bari, Italy Peter Ghazal, University of Edinburgh, UK

${ }^{*}$ Correspondence: Lyle L. Moldawer moldawer@surgery.ufl.edu

Specialty section: This article was submitted to Neonatology, a section of the journal

Frontiers in Pediatrics

Received: 12 December 2016 Accepted: 20 January 2017 Published: 07 February 2017

Citation:

Raymond SL, Stortz JA, Mira JC, Larson SD, Wynn JL and Moldawer LL (2017) Immunological Defects in Neonatal Sepsis and Potential Therapeutic Approaches. Front. Pediatr. 5:14. doi: 10.3389/fped.2017.00014 to infection and sepsis have led to unique insights into the early proinflammatory and host protective responses to sepsis. Paradoxically, this early inflammatory response in neonates, although lethal, is clearly less robust relative to children and adults. Similarly, the expression of genes involved in host protective immunity, particularly neutrophil function, is also markedly deficient. As a result, neonates have both a diminished inflammatory and protective immune response to infection which may explain their increased risk to infection, and their reduced ability to clear infections. Such studies imply that novel approaches unique to the neonate will be required for the development of both diagnostics and therapeutics in this high at-risk population.

Keywords: inflammation, innate immunity, shock, infection, host response, genomics, transcriptomics

\section{INTRODUCTION}

Neonatal sepsis is a major health-care burden worldwide, accounting for approximately 1.4 million neonatal deaths annually (1). Preterm infants are particularly susceptible to sepsis and have a higher risk of long-term complications and mortality than term infants (2). Despite advances in the delivery of neonatal intensive care, improving outcomes as well as diagnostic and prognostic accuracy in neonatal sepsis have been challenging (3).

The diagnosis of neonatal sepsis relies on the subjective interpretation of each case. This stems from a lack of specificity for clinical signs and symptoms (4) and suboptimal predictive ability of routine laboratory tests (5). Even blood cultures, the "gold-standard", result positive in fewer than $10 \%$ of cases of suspected sepsis $(6,7)$. The subjectivity of the clinicians approach to neonatal sepsis is further demonstrated by the observation that intraregional variation of antibiotic usage in the neonatal intensive care unit can range up to 40-fold (8). Underlying the diagnostic and prognostic challenges for this population is the absence of a consensus definition of neonatal sepsis to align research efforts (2). 
The classification of neonatal sepsis is dependent on timing of onset; early-onset neonatal sepsis (EOS) occurs in the first $72 \mathrm{~h}$ of life, while late-onset neonatal sepsis (LOS) occurs after the first $72 \mathrm{~h}$ and is considered to have been contracted postnatally (9). The primary etiologies of EOS remain group B streptococcal (GBS) infection, despite a reduction in vertical transmission by intrapartum antibiotic prophylaxis, and Escherichia coli, which is increasing in very low birth weight (VLBW, $<1,500 \mathrm{~g}$ birth weight) preterm neonates (3). In contrast, LOS is most commonly caused by coagulase-negative staphylococci and occurs primarily in VLBW neonates (3). The risk factors for EOS are more closely related to vertical maternal transmission (GBS colonization, premature rupture of membranes, maternal urinary tract infection, etc.), while LOS tends to be associated with the shortcomings of long-term critical care hospitalization (invasive procedures, intubation, prolonged indwelling catheters, interruption of natural barriers, etc.), as may be expected in very preterm and extremely preterm neonates (1).

The neonatal adaptive immune system lacks the capacity to support a robust response to infection (10) (Figure 1). The adaptive immune response in neonates differs dramatically from that of children and adults. Neonatal T cells have been categorized as being both anti-inflammatory and toleragenic, a functional phenotype that appears to be programed into the hematopoietic stem cell (HSC) development of neonates (11). Mold and colleagues have shown that different populations of HSCs are active at various stages of development, and neonates possess HSCs whose $\mathrm{T}$ cell lineage is biased toward tolerance (12). This premise

\section{Adaptive Immunity}

\begin{tabular}{ll}
\hline - Higher percentage of CD4 T-cells \\
- Abundant regulatory T-cells \\
- Predominance of Th17 cells \\
- Presence of anti-inflammatory and toleragenic T-cells \\
- Increased susceptibility of T-cells to apoptosis \\
- Diminished T-cell cytokine response \\
- Diminished mitogen-induce lymphocyte proliferation \\
- Diminished B cell receptor signaling \\
- Low serum immunoglobulin concentrations
\end{tabular}

Innate Immunity

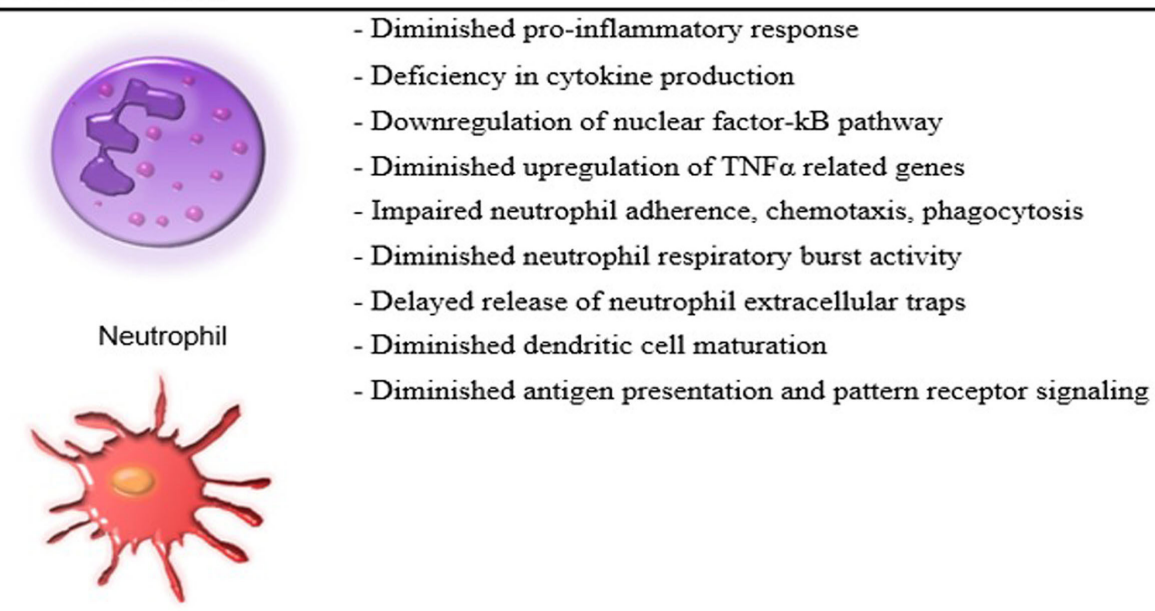

Dendritic cell

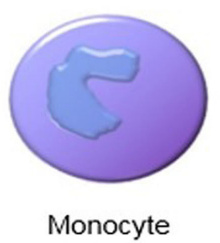

FIGURE 1 | Distinct features of the neonatal immunity. 
is also consistent with the findings of Elahi who demonstrated that immature erythroid populations $\left(\mathrm{CD} 71^{+}\right)$found in neonates are immunosuppressive and concluded that these cells increase the risk of infection (13). However, Wynn et al. demonstrated that $\mathrm{CD}_{7} 1^{+}$erythroid cell depletion, adoptive transfer of CD71 ${ }^{+}$ cells, or both (depletion followed by adoptive transfer) had no impact on murine neonatal polymicrobial sepsis survival, and $\mathrm{CD} 1^{+}$cells in human neonates were revealed to be enucleated reticulocytes (14).

Because an adaptive immune response favors tolerance and contributes little to host protective immunity, the neonate predominantly relies on an immature innate immunity (15). These deficiencies are linked to the developmental age of the neonate and place the preterm infant at the greatest risk of developing sepsis (16). Despite a significant dependence upon innate immunity, neonates have an underdeveloped innate response to infection including decreased cytokine production and reduced neutrophil and dendritic cell function as compared to adults, which further increases the risk of developing bacterial, fungal, and viral infections $(17,18)$.

\section{TRANSCRIPTOMIC RESPONSE TO NEONATAL SEPSIS}

Since 1990 and the original sequencing of the human genome, the growth of genomic research has greatly expanded our understanding of the underlying response to infection in neonates. In the past decade alone, genome-wide association studies and transcriptomic analyses have become routine and are currently being used for precision medicine initiatives. Genome-wide transcriptomics in particular have become routine discovery tools to better understand tumor and host tissue responses, either by microarray or ribonucleic acid (RNA) sequencing.

With these new tools have come new challenges (19). Bioinformatics have had difficulty keeping up with both the statistical approaches used, as well as the extraction of useable information from these vast amounts of data. Development of biomarkers based on these technologies has been especially challenging due to the initial inability to replicate the findings in confirmatory studies (20). There have been some novel approaches to overcoming the hurdles associated with high-throughput studies conducted in small data sets (21) and the difficulty in replicating the findings. Sweeney et al. have taken a meta-analysis approach using publically available datasets of septic adults and children to extract robust transcriptomic changes that are seen across a large number of individual smaller studies $(22,23)$.

Investigations into the transcriptomic responses to infection have led to identification of genomic alterations associated with both infection and developmental age $(24,25)$ and provided new approaches to diagnostics, prognostics, and therapeutics in sepsis (26). In this narrative review, we focus on the current understanding of the neonatal transcriptomic response to sepsis and how this knowledge may be used to improve our investigative and clinical approach to neonatal sepsis.

Among pediatric patients with septic shock, neonates demonstrate significant reduction in the change of gene expression representing key inflammation and immunity signaling pathways compared to infants, toddlers, and children (25). As expected, septic neonates have a significant upregulation, albeit attenuated, of several genes involved in innate immunity compared to uninfected neonates $(24,27,28)$. The neonatal innate immune response to sepsis is driven by an increased expression of neutrophils and monocytes (28). By contrast, there is a net suppression of the adaptive immune response as characterized by a decrease in expression levels by T and B cells (28). Genome-wide expression profiles of neonates differ significantly between early- and late-onset sepsis (27), suggesting that the host immune response is determined in part by the postnatal age at the onset of sepsis. Interestingly, genome-wide expression profiles of VLBW neonates with sepsis also differ between Gram-positive and Gram-negative sepsis, suggesting that the neonatal response to sepsis varies depending on the inducing pathogen (24). Similar responses have been seen in adults when exposed ex vivo to Gram-negative and Gram-positive pathogens (29).

Studies on the genomic response of whole blood or enriched blood leukocytes from neonates confirm this attenuation of early inflammatory responses. Compared to infants and children, neonates with septic shock downregulate expression of key nuclear factor kappa B pathway-related genes (25). Neonatal mice likewise have an attenuated early inflammatory response to infection compared to adults, including a diminished upregulation of tumor necrosis factor alpha (TNF $\alpha)$-related genes (30). This raises an interesting paradox. If neonates have a weakened early inflammatory response compared to adults, but early mortality is more common, there can only be a limited number of explanations. The first is that neonates are markedly more sensitive to the inflammatory signals produced early in response to microbial infection. Despite a diminished inflammatory response, that response is much more likely to result in endothelial injury, circulatory failure, organ injury, and death. An alternative explanation is that the attenuation in host inflammatory responses parallels an attenuation of host protective mechanisms. In this case, an early failure to control bacterial growth leads to rapid colonization of organs, cardiovascular failure, and death. Support for this latter hypothesis comes from genomic and functional studies on innate and adaptive immunity in neonates $(25,31)$. It is likely, however, that both processes are active.

The transcriptomic differences seen in human neonates are in agreement with transcriptional changes seen in murine models of polymicrobial sepsis in which neonatal mice exhibit increased mortality compared to young adult mice. These models demonstrate that neonates do not depend on an intact adaptive immune system to provide host protective immunity (15). In response to early sepsis, neonates also have decreased ability to recruit innate immune effector cells to the source of infection, with recruited cells having decreased ability to produce reactive oxygen species compared to adult mice (30). This is best revealed in Figure 2 which examined whole blood leukocyte gene expression from young adult and neonatal mice. Young adult mice had the characteristic increase in the gene expression of proteins involved predominantly in inflammation and innate immunity. Not only were these increases absent in 


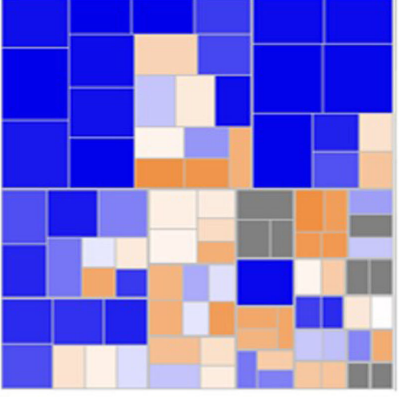

\section{Young Adult}

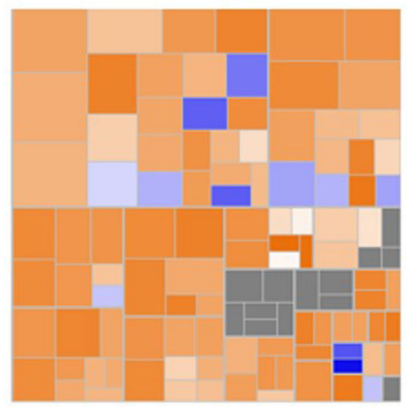

\begin{tabular}{|l|r|}
\hline \multicolumn{1}{|c|}{ Function } & $\begin{array}{r}\text { Predicted Activation State } \\
\text { Z-score }\end{array}$ \\
\hline Quantity of T lymphocytes & -4.449 \\
\hline Quantity of lymphocytes & -4.013 \\
\hline Quantity of mononuclear leukocytes & -3.493 \\
\hline Development of blood cells & -3.43 \\
\hline Development of lymphocytes & -3.417 \\
\hline Quantity of hematopoietic progenitor cells & -3.411 \\
\hline T cell development & -3.32 \\
\hline T cell homeostasis & -3.273 \\
\hline Development of mononuclear leukocytes & -3.225 \\
\hline Development of leukocytes & -3.215 \\
\hline
\end{tabular}

\begin{tabular}{|l|r|}
\hline Activation of neutrophils & 3.75 \\
\hline Activation of granulocytes & 3.675 \\
\hline Differentiation of phagocytes & 3.291 \\
\hline Adhesion of immune cells & 3.15 \\
\hline Chemotaxis of leukocytes & 3.123 \\
\hline Proliferation of mononuclear leukocytes & 2.91 \\
\hline Homing of leukocytes & 2.874 \\
\hline Quantity of hematopoietic progenitor cells & 2.866 \\
\hline Proliferation of B lymphocytes & 2.856 \\
\hline Differentiation of myeloid cells & 2.809 \\
\hline
\end{tabular}

FIGURE 2 | Pathway analysis of gene expression from blood leukocytes of neonates and young adults subjected to sepsis. Modified from Gentile et al. (30). Copyright 2014. The American Association of Immunologists, Inc. Heat maps show the gene expression of the functional category hematological systems development and function. Blue represents pathways with an overexpression of genes leading to downregulation of the pathway, whereas orange represents pathways with an overexpression of genes whose activation will lead to upregulation of the pathway. The corresponding tables show the top 10 pathways and their corresponding z-score within the functional category. Blue indicates the pathway is significantly downregulated, and red indicates the pathway is significantly upregulated.

neonatal mice, but there was also a downregulation of genes involved in the development of an adaptive immune response.

Likewise, significant reductions in proinflammatory plasma cytokine concentrations exist among neonatal mice as compared to adult mice including interleukin (IL)-1 $\alpha$, IL-1 $\beta$, IL-12p40, IL-13, TNF $\alpha$, granulocyte-macrophage colony-stimulating factor (GM-CSF), macrophage inflammatory protein-1 beta, regulated on activation normal T-cell expressed and secreted, and interferon gamma (32). Analysis $24 \mathrm{~h}$ after sepsis reveals neonatal plasma cytokine concentrations are equivalent to young adults except for IL-1 $\beta$ and IL-12p40 which remain diminished. Based on functional pathway analysis, isolated leukocytes from neonatal mice have significant downregulation of pathways $24 \mathrm{~h}$ after sepsis corresponding to the development of leukocytes, quantity of T lymphocytes, and proliferation of immune cells (30). In addition to transcriptomic differences in the response to infection, the baseline transcriptome differed significantly between neonatal and adult mice leukocytes by 5,798 probe sets. (30). The representative genes demonstrate functional suppression of the adaptive immunity and downregulation of genes in pathways involved with the activation of the innate immunity.

When evaluating these studies of sepsis in mice, it is important to note key differences between murine and human immunity. Whereas the predominating circulating leukocyte in humans is the neutrophil (50-70\%), the lymphocyte is the predominating circulating leukocyte in mice (75-90\%) (33). Also, neutrophils are an abundant source of defensins in humans, while mice lack these antimicrobial peptides (34). In addition to differences in innate immunity, humans and mice also exhibit differences in adaptive immunity. These differences include, but are not limited to, expression of $\mathrm{Fc}$ receptors, immunoglobulin isotypes and antibody class switching, and $\mathrm{T}$ cell receptor signaling and costimulation (35).

Many of these changes in gene expression are recapitulated phenotypically. Neonates exhibit defective neutrophil function compared to adults including adherence, chemotaxis, phagocytosis, neutrophil respiratory burst activity (NRBA), and release of neutrophil extracellular traps (NETs) (36-40). Merry and colleagues demonstrated that neutrophils from healthy neonates have impaired chemotaxis compared to healthy adults and even greater impairment was observed among septic neonates (39). At birth, neutrophil phagocytosis is significantly reduced in both preterm and term neonates as compared to adults; however, this impairment appears to resolve by 3 days after birth (38). This may further explain some of the observed differences in host response to early- and late-onset sepsis, although an additional explanation may be the use of umbilical cord blood (UCB) compared to peripheral blood in this study. UCB may be impacted by administration of antepartum antibiotics as well as the physiological stresses of labor. Healthy preterm neonates have fewer circulating neutrophils compared to term neonates (41) and exhibit a lower percentage of NRBA compared to term neonates and 
adults (37). In samples from septic patients, both term and preterm neonates demonstrate diminished NRBA. Neonatal neutrophils additionally fail to form NETs following an hour of ex vivo lipopolysaccharide (LPS) stimulation, whereas adult neutrophils readily form NETs which bind and kill bacteria extracellularly (40). However, neonatal neutrophils began to form NETs following $2 \mathrm{~h}$ of LPS stimulation and nearly reach adult levels by $3 \mathrm{~h}$ of stimulation (42).

\section{FUTURE DIRECTIONS}

Successful modulation of the neonatal immune system to reduce the frequency of sepsis, sepsis mortality, and sepsis survivor morbidity would represent substantial advances in the field. Despite multiple attempts to modulate neonatal immunity in an effort to improve sepsis outcomes in neonates, most therapies have been largely unsuccessful to date (43). This is not particularly surprising given the equivalent failures of immune modulation in adult sepsis, which have prompted clinical trials with rapid molecular assessments of immune status and provision of the appropriate immunomodulatory strategy (anti-inflammatory or immune stimulation) (https:/clinicaltrials.gov/ct2/show/NCT02576457). Previous immunomodulatory strategies which have been studied in neonates include granulocyte transfusions, administration of GM-CSF, intravenous immunoglobulin, activated protein C, glutamine, pentoxifylline, anti-endotoxin antibodies, probiotics, and breast milk (43) (Table 1). With the exceptions of breast milk and bovine lactoferrin, these therapies have shown minimal to no reduction in sepsis incidence, and no intervention is associated with an improvement in sepsis-related mortality (43).

Therapeutics aimed at preventing or treating neonatal sepsis must take into consideration the unique immunological status of the subject. One example of this is the observation that healthy preterm neonates have elevated blood concentrations of IL-18 (63), a proinflammatory member of the IL- 1 superfamily. Healthy adults do not manifest high concentrations of circulating IL-18 (64), and their increase in sepsis is markedly lower than the increases seen in neonates (65). Targeting the IL-18/IL-17A axis through the use of neutralizing IL-17 receptor antibodies represents a novel approach to treating neonatal sepsis (59). While IL-18 is known to exert proinflammatory effects such as increased neutrophil phagocytosis and production of reactive oxygen species, paradoxically, IL-18-null (IL-18 ${ }^{-/-}$) neonatal mice demonstrated markedly improved survival and reduced bacteremia in comparison to wild-type neonatal mice when challenged with polymicrobial sepsis (59). Unlike human preterm neonates, healthy neonatal mice do not exhibit increased circulating IL-18. When IL-18 was given to septic mice to mimic the human condition, mortality was dramatically increased compared to septic mice alone and was associated with increased bacteremia, intestinal injury, and an increased systemic inflammatory response predominated by IL-17A. The deleterious effects of IL-18 on neonatal sepsis survival were dependent upon IL-1R1 signaling and IL-17A production by gamma delta cells in the intestine and lung (59). Compared to wild-type or isotype control treated mice, transgenic mice lacking IL-17A or wild-type mice that received antibody-mediated receptor blockade of IL-17A through IL-17A receptor or cytokine neutralizing antibodies exhibited markedly reduced mortality to sepsis (59). Currently, two antibodies directed against IL-17A (secukinumab and ixekizumab) have obtained FDA approval for use in other inflammatory diseases, and an additional antibody against IL-17A receptor (brodalumab) is currently awaiting final FDA approval. These therapies may prove beneficial in septic neonates.

The prevention rather than treatment of sepsis is an alternative approach and would be expected to have a significant benefit over the current reactive paradigm. Defined exposure to non-infectious components of bacteria that are recognized

TABLE 1 | Summary of strategies aimed at improving the neonatal immune response.

\begin{tabular}{lll}
\hline Strategy & Proposed mechanism & Reference \\
\hline Granulocyte transfusions & Addition of functional granulocytes & (44) \\
\hline GM-CSF, G-CSF & Stimulates proliferation, differentiation, and functional activity of myeloid precursors & (45, 46) \\
\hline Intravenous immunoglobulin & Increase antibody titer and potential antigen-antibody interactions & (47-50) \\
\hline Activated protein C & Anti-inflammatory and anti-coagulant properties & (51, 52) \\
\hline Glutamine & Enhance function of immune cells & (53, 54) \\
\hline Pentoxifylline & Inhibit release of TNF $\alpha$ & (55) \\
\hline Anti-endotoxin antibodies & Inhibit deleterious effects of endotoxins & (56) \\
\hline Probiotics & Maintain integrity of the intestinal barrier function & (57) \\
\hline Breast millK & Provides immunoglobulin A, lactoferrin, oligosaccharides & (58) \\
\hline Anti-IL17A, anti-IL17A receptor antibodies & Inhibit pathological proinflammatory effects of IL-18 \\
\hline Toll-like receptor agonists & Augment innate immunity & (59) \\
\hline Topical emollient & Protect against skin breakdown, prevent pathogens entry & (15) \\
\hline Lactoferrin & Iron sequestration, disruption of microbial cell membranes & (60) \\
\hline FFP & Provides humoral immune factors & (61) \\
\hline
\end{tabular}

GM-CSF, granulocyte-macrophage colony-stimulating factor; G-CSF, granulocyte colony-stimulating factor; FFP, fresh frozen plasma; IL, interleukin; TNF $\alpha$, tumor necrosis factor alpha. 
by the innate immune system is one approach being considered as a means to positively modify neonatal immune responses. Of the adjuvant therapies currently being studied, toll-like receptor (TLR) agonists appear most promising (66). TLRs play a vital role in early recognition of microbial invasion and activation of the innate immunity (67). TLRs are membranespanning receptors present on the cell surface and within intracellular vesicles of leukocytes and other non-immune cell populations such as endothelial cells and fibroblasts (68). Stimulation of these receptors occurs through the binding of ligands, specifically, pathogen-associated molecular patterns (PAMPs) (69). PAMPs may include components of either the bacterial or fungal cell wall or membrane such as LPS, peptidoglycan, or flagellin, or intracellular components such as single- or double-stranded RNA or deoxyribonucleic acid. Activation of these receptors induces downstream molecular signaling events which ultimately triggers the production of inflammatory cytokines, type I interferons, chemokines, and antimicrobial peptides (70).

Toll-like receptor agonists, in particular those affecting TLR 4 and TLR 7/8, have been shown to augment innate immunity, magnify but abbreviate the early systemic inflammatory response, reduce bacteremia, and increase survival to polymicrobial sepsis in neonatal murine models (15). Burl and colleagues also demonstrated that in vitro stimulation of newborn cord blood with TLR agonists led to significant production of TNF $\alpha$, IL-6, IL-1 $\beta$, and IL-10 (71). Interestingly, several first-generation inactivated and attenuated vaccines including rabies, typhoid, and Bacillus Calmette-Guérin (BCG) possess inherent TLR activity (72). Hence, the inclusion of adjuvants in vaccines has provided non-specific heterologous benefits and enhanced immune responses in traditionally poor-responding populations such as neonates. When BCG was administered at birth to newborns in sub-Saharan Africa, there was a $41 \%$

\section{REFERENCES}

1. Shane AL, Stoll BJ. Neonatal sepsis: progress towards improved outcomes. J Infect (2014) 68(Suppl 1):S24-32. doi:10.1016/j.jinf.2013.09.011

2. Wynn JL. Defining neonatal sepsis. Curr Opin Pediatr (2016) 28:135-40. doi:10.1097/MOP.0000000000000315

3. Camacho-Gonzalez A, Spearman PW, Stoll BJ. Neonatal infectious diseases: evaluation of neonatal sepsis. Pediatr Clin North Am (2013) 60:367-89. doi:10.1016/j.pcl.2012.12.003

4. Gerdes JS. Diagnosis and management of bacterial infections in the neonate. Pediatr Clin North Am (2004) 51:939-59, viii-ix. doi:10.1016/j. pcl.2004.03.009

5. Benitz WE. Adjunct laboratory tests in the diagnosis of early-onset neonatal sepsis. Clin Perinatol (2010) 37:421-38. doi:10.1016/j.clp.2009.12.001

6. Cantey JB, Wozniak PS, Sanchez PJ. Prospective surveillance of antibiotic use in the neonatal intensive care unit: results from the SCOUT study. Pediatr Infect Dis J (2015) 34:267-72. doi:10.1097/INF.0000000000000542

7. Hornik CP, Fort P, Clark RH, Watt K, Benjamin DK Jr, Smith PB, et al. Early and late onset sepsis in very-low-birth-weight infants from a large group of neonatal intensive care units. Early Hum Dev (2012) 88(Suppl 2):S69-74. doi:10.1016/S0378-3782(12)70019-1

8. Schulman J, Dimand RJ, Lee HC, Duenas GV, Bennett MV, Gould JB. Neonatal intensive care unit antibiotic use. Pediatrics (2015) 135:826-33. doi:10.1542/peds.2014-3409 reduction in all-cause mortality at 12 months among VLBW neonates, which was attributed to fewer cases of neonatal sepsis, respiratory infections, and fever (73).

\section{CONCLUSION}

Neonatal sepsis is prominent cause of morbidity and mortality. A clear understanding of the neonatal response to sepsis represents a critical knowledge gap that greatly limits the opportunity to discover novel diagnostics and therapies to treat and potentially prevent this devastating disease. Evaluation of the transcriptomic response of blood leukocyte populations offers both a global view of the neonatal response to infection and sepsis, and the potential for identification of novel therapeutic opportunities, diagnostic tests, and prognostic markers. Accurate biomarkers would facilitate both targeted treatment, thus avoiding the overuse of empiric antibiotics in non-septic neonates, and an enrichment strategy that facilitates better selection of study participants for future clinical trials.

\section{AUTHOR CONTRIBUTIONS}

All the authors contributed extensively to the work presented in this paper. SR, JS, and JM wrote the manuscript. SL, JW, and LM gave conceptual advice and edited the manuscript.

\section{FUNDING}

This work was supported by K08 GM106143, R01 GM097531, and P50 GM111152 awarded by the National Institute of General Medical Sciences (NIGMS). JS and JM were supported by a NIGMS post-doctoral training grant in burns and trauma (T32 GM008721).

9. Shane AL, Stoll BJ. Recent developments and current issues in the epidemiology, diagnosis, and management of bacterial and fungal neonatal sepsis. Am J Perinatol (2013) 30:131-41. doi:10.1055/s-0032-1333413

10. Zaghouani H, Hoeman CM, Adkins B. Neonatal immunity: faulty T-helpers and the shortcomings of dendritic cells. Trends Immunol (2009) 30:585-91. doi:10.1016/j.it.2009.09.002

11. Gibbons D, Fleming P, Virasami A, Michel ML, Sebire NJ, Costeloe K, et al. Interleukin-8 (CXCL8) production is a signatory $\mathrm{T}$ cell effector function of human newborn infants. Nat Med (2014) 20:1206-10. doi:10.1038/ nm. 3670

12. Mold JE, Venkatasubrahmanyam S, Burt TD, Michaelsson J, Rivera JM, Galkina SA, et al. Fetal and adult hematopoietic stem cells give rise to distinct T cell lineages in humans. Science (2010) 330:1695-9. doi:10.1126/ science. 1196509

13. Elahi S, Ertelt JM, Kinder JM, Jiang TT, Zhang X, Xin L, et al. Immunosuppressive CD71+ erythroid cells compromise neonatal host defence against infection. Nature (2013) 504:158-62. doi:10.1038/nature12675

14. Wynn JL, Scumpia PO, Stocks BT, Romano-Keeler J, Alrifai MW, Liu JH, et al. Neonatal CD71+ erythroid cells do not modify murine sepsis mortality. J Immunol (2015) 195:1064-70. doi:10.4049/jimmunol.1500771

15. Wynn JL, Scumpia PO, Winfield RD, Delano MJ, Kelly-Scumpia K, Barker $\mathrm{T}$, et al. Defective innate immunity predisposes murine neonates to poor sepsis outcome but is reversed by TLR agonists. Blood (2008) 112:1750-8. doi:10.1182/blood-2008-01-130500 
16. Palmeira P, Quinello C, Silveira-Lessa AL, Zago CA, Carneiro-Sampaio M. IgG placental transfer in healthy and pathological pregnancies. Clin Dev Immunol (2012) 2012:985646. doi:10.1155/2012/985646

17. Kollmann TR, Crabtree J, Rein-Weston A, Blimkie D, Thommai F, Wang $\mathrm{XY}$, et al. Neonatal innate TLR-mediated responses are distinct from those of adults. J Immunol (2009) 183:7150-60. doi:10.4049/jimmunol. 0901481

18. Levy O. Innate immunity of the newborn: basic mechanisms and clinical correlates. Nat Rev Immunol (2007) 7:379-90. doi:10.1038/nri2075

19. Mira JC, Moldawer LL. Sepsis diagnostics: from discovery to application. Crit Care Med (2017) 45:129-30. doi:10.1097/CCM.00000000000 02117

20. Dopazo J. Genomics and transcriptomics in drug discovery. Drug Discov Today (2014) 19:126-32. doi:10.1016/j.drudis.2013.06.003

21. Martini M, Vecchione L, Siena S, Tejpar S, Bardelli A. Targeted therapies: how personal should we go? Nat Rev Clin Oncol (2011) 9:87-97. doi:10.1038/ nrclinonc.2011.164

22. Sweeney TE, Khatri P. Benchmarking sepsis gene expression diagnostics using public data. Crit Care Med (2017) 45:1-10. doi:10.1097/ CCM.0000000000002021

23. Sweeney TE, Shidham A, Wong HR, Khatri P. A comprehensive timecourse-based multicohort analysis of sepsis and sterile inflammation reveals a robust diagnostic gene set. Sci Transl Med (2015) 7:287ra71. doi:10.1126/ scitranslmed.aaa5993

24. Cernada M, Serna E, Bauerl C, Collado MC, Perez-Martinez G, Vento M. Genome-wide expression profiles in very low birth weight infants with neonatal sepsis. Pediatrics (2014) 133:e1203-11. doi:10.1542/peds. 2013-2552

25. Wynn JL, Cvijanovich NZ, Allen GL, Thomas NJ, Freishtat RJ, Anas N, et al. The influence of developmental age on the early transcriptomic response of children with septic shock. Mol Med (2011) 17:1146-56. doi:10.2119/ molmed.2011.00169

26. Srinivasan L, Kirpalani H, Cotten CM. Elucidating the role of genomics in neonatal sepsis. Semin Perinatol (2015) 39:611-6. doi:10.1053/j. semperi.2015.09.008

27. Wynn JL, Guthrie SO, Wong HR, Lahni P, Ungaro R, Lopez MC, et al. Postnatal age is a critical determinant of the neonatal host response to sepsis. Mol Med (2015) 21:496-504. doi:10.2119/molmed.2015.00064

28. Smith CL, Dickinson P, Forster T, Craigon M, Ross A, Khondoker MR, et al. Identification of a human neonatal immune-metabolic network associated with bacterial infection. Nat Commun (2014) 5:4649. doi:10.1038/ ncomms 5649

29. Feezor RJ, Oberholzer C, Baker HV, Novick D, Rubinstein M, Moldawer $\mathrm{LL}$, et al. Molecular characterization of the acute inflammatory response to infections with Gram-negative versus Gram-positive bacteria. Infect Immun (2003) 71:5803-13. doi:10.1128/IAI.71.10.5803-5813.2003

30. Gentile LF, Nacionales DC, Lopez MC, Vanzant E, Cuenca A, Cuenca AG, et al. Protective immunity and defects in the neonatal and elderly immune response to sepsis. J Immunol (2014) 192:3156-65. doi:10.4049/ jimmunol.1301726

31. Mathias B, Mira JC, Rehfuss JP, Rincon JC, Ungaro R, Nacionales DC, et al. LPS stimulation of cord blood reveals a newborn-specific neutrophil transcriptomic response and cytokine production. Shock (2016). doi:10.1097/ SHK.0000000000000800

32. Wynn JL, Scumpia PO, Delano MJ, O'Malley KA, Ungaro R, Abouhamze A, et al. Increased mortality and altered immunity in neonatal sepsis produced by generalized peritonitis. Shock (2007) 28:675-83. doi:10.1097/ SHK.0b013e3180556d09

33. Doeing DC, Borowicz JL, Crockett ET. Gender dimorphism in differential peripheral blood leukocyte counts in mice using cardiac, tail, foot, and saphenous vein puncture methods. BMC Clin Pathol (2003) 3:3. doi:10.1186/1472-6890-3-3

34. Eisenhauer PB, Lehrer RI. Mouse neutrophils lack defensins. Infect Immun (1992) 60:3446-7.

35. Mestas J, Hughes CC. Of mice and not men: differences between mouse and human immunology. J Immunol (2004) 172:2731-8. doi:10.4049/ jimmunol.172.5.2731
36. Anderson DC, Hughes BJ, Smith CW. Abnormal mobility of neonatal polymorphonuclear leukocytes. Relationship to impaired redistribution of surface adhesion sites by chemotactic factor or colchicine. J Clin Invest (1981) 68:863-74. doi:10.1172/JCI110341

37. Drossou V, Kanakoudi F, Tzimouli V, Sarafidis K, Taparkou A, Bougiouklis D, et al. Impact of prematurity, stress and sepsis on the neutrophil respiratory burst activity of neonates. Biol Neonate (1997) 72:201-9. doi:10.1159/ 000244485

38. Filias A, Theodorou GL, Mouzopoulou S, Varvarigou AA, Mantagos S, Karakantza M. Phagocytic ability of neutrophils and monocytes in neonates. BMC Pediatr (2011) 11:29. doi:10.1186/1471-2431-11-29

39. Merry C, Puri P, Reen DJ. Defective neutrophil actin polymerisation and chemotaxis in stressed newborns. J Pediatr Surg (1996) 31:481-5. doi:10.1016/S0022-3468(96)90479-0

40. Yost CC, Cody MJ, Harris ES, Thornton NL, McInturff AM, Martinez ML, et al. Impaired neutrophil extracellular trap (NET) formation: a novel innate immune deficiency of human neonates. Blood (2009) 113:6419-27. doi:10.1182/blood-2008-07-171629

41. Prosser A, Hibbert J, Strunk T, Kok CH, Simmer K, Richmond P, et al. Phagocytosis of neonatal pathogens by peripheral blood neutrophils and monocytes from newborn preterm and term infants. Pediatr Res (2013) 74:503-10. doi:10.1038/pr.2013.145

42. Marcos V, Nussbaum C, Vitkov L, Hector A, Wiedenbauer EM, Roos D, et al. Delayed but functional neutrophil extracellular trap formation in neonates. Blood (2009) 114:4908-11; author reply 11-2. doi:10.1182/ blood-2009-09-242388

43. Wynn JL, Neu J, Moldawer LL, Levy O. Potential of immunomodulatory agents for prevention and treatment of neonatal sepsis. J Perinatol (2009) 29:79-88. doi:10.1038/jp.2009.48

44. Pammi M, Brocklehurst P. Granulocyte transfusions for neonates with confirmed or suspected sepsis and neutropaenia. Cochrane Database Syst Rev (2011) (10):CD003956. doi:10.1002/14651858.CD003956.pub2

45. Carr R, Brocklehurst P, Dore CJ, Modi N. Granulocyte-macrophage colony stimulating factor administered as prophylaxis for reduction of sepsis in extremely preterm, small for gestational age neonates (the PROGRAMS trial): a single-blind, multicentre, randomised controlled trial. Lancet (2009) 373:226-33. doi:10.1016/S0140-6736(09)60071-4

46. Mathias B, Szpila BE, Moore FA, Efron PA, Moldawer LL. A review of GM-CSF therapy in sepsis. Medicine (2015) 94(50):e2044. doi:10.1097/ MD.0000000000002044

47. INIS Collaborative Group, Brocklehurst P, Farrell B, King A, Juszczak E, Darlow B, et al. Treatment of neonatal sepsis with intravenous immune globulin. N Engl J Med (2011) 365:1201-11. doi:10.1056/NEJMoa1100441

48. Ohlsson A, Lacy JB. Intravenous immunoglobulin for suspected or proven infection in neonates. Cochrane Database Syst Rev (2015) (3):CD001239. doi:10.1002/14651858.CD001239.pub5

49. Shah PS, Kaufman DA. Antistaphylococcal immunoglobulins to prevent staphylococcal infection in very low birth weight infants. Cochrane Database Syst Rev (2009) (2):CD006449. doi:10.1002/14651858.CD006449.pub2

50. Patel M, Kaufman DA. Anti-lipoteichoic acid monoclonal antibody (pagibaximab) studies for the prevention of staphylococcal bloodstream infections in preterm infants. Expert Opin Biol Ther (2015) 15:595-600. d oi: $10.1517 / 14712598.2015 .1019857$

51. Goldstein B, Nadel S, Peters M, Barton R, Machado F, Levy H, et al. ENHANCE: results of a global open-label trial of drotrecogin alfa (activated) in children with severe sepsis. Pediatr Crit Care Med (2006) 7:200-11. doi:10.1097/01.PCC.0000217470.68764.36

52. Kylat RI, Ohlsson A. Recombinant human activated protein $\mathrm{C}$ for severe sepsis in neonates. Cochrane Database Syst Rev (2012) (4):CD005385. doi:10.1002/14651858.CD005385.pub3

53. Poindexter BB, Ehrenkranz RA, Stoll BJ, Wright LL, Poole WK, Oh W, et al. Parenteral glutamine supplementation does not reduce the risk of mortality or late-onset sepsis in extremely low birth weight infants. Pediatrics (2004) 113:1209-15. doi:10.1542/peds.113.5.1209

54. Moe-Byrne T, Brown JV, McGuire W. Glutamine supplementation to prevent morbidity and mortality in preterm infants. Cochrane Database Syst Rev (2016) (4):CD001457. doi:10.1002/14651858.CD001457.pub6 
55. Akdag A, Dilmen U, Haque K, Dilli D, Erdeve O, Goekmen T. Role of pentoxifylline and/or IgM-enriched intravenous immunoglobulin in the management of neonatal sepsis. Am J Perinatol (2014) 31:905-12. doi:10.1055/ s-0033-1363771

56. Adhikari M, Coovadia HM, Gaffin SL, Brock-Utne JG, Marivate M, Pudifin DJ. Septicaemic low birthweight neonates treated with human antibodies to endotoxin. Arch Dis Child (1985) 60:382-4. doi:10.1136/adc.60.4.382

57. Hartel C, Pagel J, Rupp J, Bendiks M, Guthmann F, Rieger-Fackeldey E, et al. Prophylactic use of Lactobacillus acidophilus/Bifidobacterium infantis probiotics and outcome in very low birth weight infants. J Pediatr (2014) 165:285-9.e1. doi:10.1016/j.jpeds.2014.04.029

58. Patel AL, Johnson TJ, Engstrom JL, Fogg LF, Jegier BJ, Bigger HR, et al. Impact of early human milk on sepsis and health-care costs in very low birth weight infants. J Perinatol (2013) 33:514-9. doi:10.1038/jp.2013.2

59. Wynn JL, Wilson CS, Hawiger J, Scumpia PO, Marshall AF, Liu JH, et al. Targeting IL-17A attenuates neonatal sepsis mortality induced by IL-18. Proc Natl Acad Sci U S A (2016) 113:E2627-35. doi:10.1073/pnas.1515793113

60. Cleminson J, McGuire W. Topical emollient for preventing infection in preterm infants. Cochrane Database Syst Rev (2016) (1):CD001150. doi:10.1002/14651858.CD001150.pub3

61. Manzoni P, Rinaldi M, Cattani S, Pugni L, Romeo MG, Messner H, et al. Bovine lactoferrin supplementation for prevention of late-onset sepsis in very low-birth-weight neonates: a randomized trial. JAMA (2009) 302:1421-8. doi:10.1001/jama.2009.1403

62. Acunas BA, Peakman M, Liossis G, Davies ET, Bakoleas B, Costalos C, et al. Effect of fresh frozen plasma and gammaglobulin on humoral immunity in neonatal sepsis. Arch Dis Child Fetal Neonatal Ed (1994) 70:F182-7. doi:10.1136/fn.70.3.F182

63. Sood BG, Shankaran S, Schelonka RL, Saha S, Benjamin DK Jr, Sanchez PJ, et al. Cytokine profiles of preterm neonates with fungal and bacterial sepsis. Pediatr Res (2012) 72:212-20. doi:10.1038/pr.2012.56

64. Kleiner G, Marcuzzi A, Zanin V, Monasta L, Zauli G. Cytokine levels in the serum of healthy subjects. Mediators Inflamm (2013) 2013:434010. doi:10.1155/2013/434010

65. Grobmyer SR, Lin E, Lowry SF, Rivadeneira DE, Potter S, Barie PS, et al. Elevation of IL-18 in human sepsis. J Clin Immunol (2000) 20:212-5. doi: 10.1023/A:1006641630904
66. Savva A, Roger T. Targeting toll-like receptors: promising therapeutic strategies for the management of sepsis-associated pathology and infectious diseases. Front Immunol (2013) 4:387. doi:10.3389/fimmu.2013.00387

67. Medzhitov R. Recognition of microorganisms and activation of the immune response. Nature (2007) 449:819-26. doi:10.1038/nature06246

68. Cuenca AG, Wynn JL, Moldawer LL, Levy O. Role of innate immunity in neonatal infection. Am J Perinatol (2013) 30:105-12. doi:10.1055/s-00321333412

69. Raymond SL, Holden DC, Mira JC, Stortz JA, Loftus TJ, et al. Microbial recognition and danger signals in sepsis and trauma. Biochimica et Biophysica Acta (2017) (17):30026-1. doi:10.1016/j.bbadis.2017.01.013

70. Akira S, Uematsu S, Takeuchi O. Pathogen recognition and innate immunity. Cell (2006) 124:783-801. doi:10.1016/j.cell.2006.02.015

71. Burl S, Townend J, Njie-Jobe J, Cox M, Adetifa UJ, Touray E, et al. Agedependent maturation of toll-like receptor-mediated cytokine responses in Gambian infants. PLoS One (2011) 6:e18185. doi:10.1371/journal. pone.0018185

72. Duthie MS, Windish HP, Fox CB, Reed SG. Use of defined TLR ligands as adjuvants within human vaccines. Immunol Rev (2011) 239:178-96. doi:10.1111/j.1600-065X.2010.00978.x

73. Aaby P, Roth A, Ravn H, Napirna BM, Rodrigues A, Lisse IM, et al. Randomized trial of BCG vaccination at birth to low-birth-weight children: beneficial nonspecific effects in the neonatal period? J Infect Dis (2011) 204:245-52. doi:10.1093/infdis/jir240

Conflict of Interest Statement: The authors declare that the research was conducted in the absence of any commercial or financial relationships that could be construed as a potential conflict of interest.

Copyright (c) 2017 Raymond, Stortz, Mira, Larson, Wynn and Moldawer. This is an open-access article distributed under the terms of the Creative Commons Attribution License (CC BY). The use, distribution or reproduction in other forums is permitted, provided the original author(s) or licensor are credited and that the original publication in this journal is cited, in accordance with accepted academic practice. No use, distribution or reproduction is permitted which does not comply with these terms. 